\title{
THE FUTURE ROLE OF AGRICULTURE IN MULTIFUNCTIONAL RURAL DEVELOPMENT: THE CASE OF ITALY
}

\author{
Davide Viaggi \\ University of Bologna davide.viaggi@ unibo.it
}

\begin{abstract}
This paper addresses the issue of the role of agriculture in multifunctional rural development in Italy. Italy is characterised by high heterogeneity in terms of territorial composition, rural areas and the role of agriculture. The paper reviews the main multifunctionality concerns in Italy, by discussing rural development issues and policies and addressing the role of agriculture in such a context. The further development of agriculture and related future issues are then discussed, both in terms of dominant themes and most relevant policy design issues.
\end{abstract}

Key words: multifunctionality, Italy, agriculture, rural development

\section{Introduction and objectives}

Italy is characterised by high heterogeneity in territorial characteristics, including a wide range of climatic and ecologic conditions (lowlands, mountains, coastal and internal areas, as well as rather fertile and almost arid areas, etc.). The rural areas and Italian agriculture reflect this heterogeneity. The prevailing character, however, at least in the policy discourse and public perception, is that of high cost, high quality production, embedded in a rich cultural and natural rural environment, strongly determined and conditioned by its long term historical development path.

In this context, the issue of multifunctionality has been central to the discussion regarding the development of rural areas over the past decade. A major role in this discussion has been played by agriculture and related policies.

The aim of this paper is to review the role of agriculture in multifunctional development of rural areas in Italy.

The paper is organised as follows: after a review of past trends and the present situation (section 2), the paper analyses future expected changes in the farming sector (sector 3), followed by a discussion of future multifunctionality issues in section 4 . The paper ends with some conclusions.

\section{Current situation and past trends ${ }^{1}$}

\subsection{Role and structure of the agricultural sector}

The Italian agricultural area is about 30 million hectares, with a relatively low share of lowlands (23\%) compared with hilly and mountainous areas. Agricultural areas account for between $37 \%$ of total area in the North and $44 \%$ in the South. About half of the total agricultural area is cultivated with crops. The ratio between population and agricultural area is of about 400 inhabitants/100 hectares.

The economic role of agriculture is confined to about $2 \%$ of the total value added, and $5.3 \%$ of total employment (2007). However, both figures are above the EU25 average , denoting the relatively important role of agriculture.

In 2007, there were about 1.7 million agricultural holdings in Italy. (Table 1).

Of this, about $73 \%$ are below 5 hectares in size, denoting a small average structure and the presence of a large share of micro-holdings. In recent decades, the agricultural sector has been characterised by a decrease in the total number of farms. The decrease has been particularly evident in the smallest size classes, while the average sized farms are rather stable in number and there is an increase of the number of farms in the highest size classes. The large majority (almost $100 \%$ ) of agricultural holders are natural persons. However, the share of legal entities with agricultural holdings has grown steadily in recent years. The age of the farmer population is rather high, with about $44 \%$ of the farmers being above 65 years of age. The number of farmers below 35 is small and continues to decline. The labour force is composed of approximately 1.3 million agricultural working units, which is less than 1 working unit per holding. The number of physical persons involved in agriculture is, however, much higher with a total of more than 3 million in 2007. Of these, a large majority are family farm members.

In spite of the emphasis on diversification and multifunctionality, only a minority of farms have gainful

1 The main source of information for this section is INEA, 2008. Check this source for the original source of information, mostly ISTAT (Istituto Nazionale di Statistica). 
Table 1. Key indicators in farm structures and labour in Italian agriculture

\begin{tabular}{|l|r|r|r|r|r|}
\hline & 1990 & 1995 & 2000 & 2005 & 2007 \\
\hline $\begin{array}{l}\text { Number of agricultural } \\
\text { holdings (000) }\end{array}$ & 2664.55 & 2482.1 & 2153.72 & 1728.53 & 1679.44 \\
\hline $\begin{array}{l}\text { Agricultural holdings with } \\
\text { agricultural area < 5 ha (000) }\end{array}$ & 2099.05 & 1938.26 & 1687.04 & 1271.66 & 1230.7 \\
\hline $\begin{array}{l}\text { Agricultural holdings with } \\
\text { agricultural area > 50 ha (000) }\end{array}$ & 38.37 & 40.25 & 36.54 & 38.62 & 40.01 \\
\hline $\begin{array}{l}\text { Agricultural holders being } \\
\text { a natural person (000) }\end{array}$ & 2646.53 & 2470.57 & 2137.72 & 1699.46 & 1663.51 \\
\hline $\begin{array}{l}\text { Agricultural holders } \\
<35 \text { years old (000) }\end{array}$ & 137.59 & 110.21 & 110.6 & 56.49 & 49.07 \\
\hline $\begin{array}{l}\text { Agricultural holders } \\
>=65 \text { years old (000) }\end{array}$ & 850.95 & 912.29 & 825.95 & 734.95 & 740.54 \\
\hline Total farm labour force (000) & 1923.99 & 1818.02 & 1364.92 & 1374.26 & 1302.18 \\
\hline Family farm labour force (000) & 5197.21 & 4695.58 & 3888.22 & 3127.46 & 3056.54 \\
\hline $\begin{array}{l}\text { Agricultural holdings with another } \\
\text { gainful activity than agricultural } \\
\text { production (\%) }\end{array}$ & & & 8.8 & 6.1 & 6.4 \\
\hline
\end{tabular}

Source: Eurostat website, 2010.

activity other than farming, and the share is declining, pointing to a process of specialisation.

The agro-industrial system is very strong in Italy with a total value added of about 240 billion euros, 10 times that of the agricultural sector, and about $8.3 \%$ of the value added of the industrial sector. The total number of employees is about 0,5 million. The main categories of products of the food industry (based on value added) are: Diet foods and other categories, milk and dairy, confectionery, and wine.

Agriculture and the agri-food industry are generally very connected to each other. A large share of the agricultural production is processed or traded by the co-operative agrifood industry, particularly in the North. Many high-quality food products (e.g. Parmiggiano-Reggiano cheese) owe their specificities to a combination of agricultural and processing prescriptions. In the perception of the general public, agriculture and small agri-food industries are the main distinguishing features of Italian rural areas. Most marketing strategies in the agricultural and food sectors are more or less explicitly related to origin (e.g. for wine and most certified quality products). While the population which depends directly on agricultural is limited to about $5 \%$, a larger share of (rural) households are still connected to agriculture through assets (land, house) property or indirect work-related activities (agri-food and related industries).

\subsection{Specificities of different rural areas}

This very general picture is actually characterised by a high degree of territorial differentiation, which also reflects the role of agriculture in rural development. The "Piano Strategico Nazionale per lo sviluppo rurale" (National strategic plan for rural development, MiPAAF, 2009) identifies three main typologies of rural areas in addition to urban areas (Figure 1)

Urban areas include $43 \%$ of the Italian population and are characterised by a strong role of industry and services.
Agriculture is mostly relevant in the surroundings of large urban settlements, which are potentially important shortdistance markets for high quality products. While the role of agricultural employment in these areas is low, or negligible, the presence of food manufacturing is rather high, with about $30 \%$ of employment located in these areas. These are the areas experiencing the highest pressure from urbanisation and, as a consequence, higher land prices and a greater share of land subtracted from agriculture ($15 \%$ of Usable Agricultural Area, UAA, in a decade). The presence of Natura 2000 sites in these areas is rather low, while there is an important share of land vulnerable to nitrates according to the nitrate directive. Due to the vicinity of town centres, the infrastructure endowment is rather good, as well as tourism and hospitality facilities.

Rural areas with intensive specialised agriculture are the most important agricultural areas of the country. They occupy mainly plain areas in the North. They include only about $22 \%$ of the total national population and $24 \%$ of the UAA, but $29 \%$ of agricultural employees, $30 \%$ of the agro-food industry and account for $38 \%$ of the national agricultural value added. They tend to be densely populated areas, with a younger and growing population $(+10 \%$ in the past decade). Most of the area is composed of agricultural

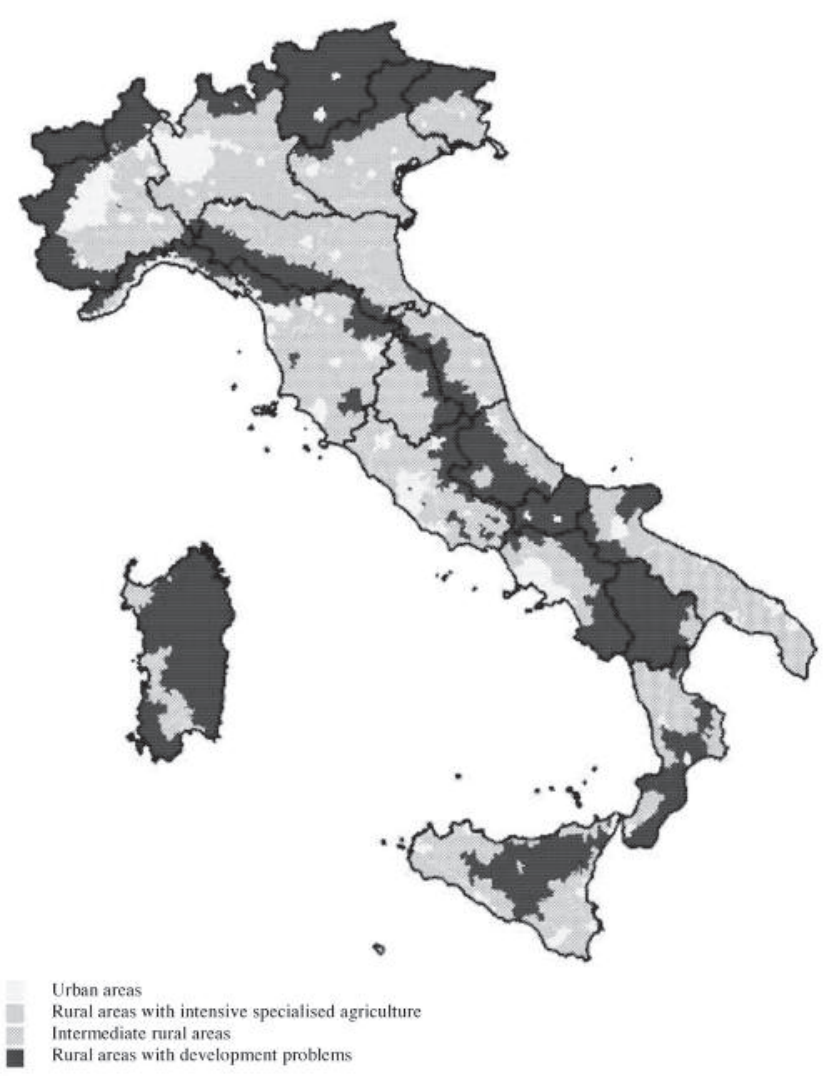

Figure 1. Typologies of rural areas in Italy 
land $(\mathrm{UAA}=62 \%)$ and the economic system is strongly specialised in agriculture, with high productivity (gross revenue per hectare above 5000 euro/year). The Agro-food industry is also strong in the rural areas, with important chain and district connections with agriculture. However, small industries and other entrepreneurial activities are also very relevant in these areas. Rural areas with intensive specialised agriculture are also important for environmental concerns, in particular because they include $35 \%$ of the national areas classified as vulnerable to nitrates. While tourism and hospitality infrastructures are generally good, other infrastructures are below the national average.

Intermediate rural areas are mostly located in hilly and mountainous areas. They include $24 \%$ of the national population and $32 \%$ of the national surface area. The population is growing in these areas $(+6 \%$ in a decade), but is affected by problems related to ageing. Agriculture is important in these areas, with a gross production of approximately 2200 euro/ha. However, the sector is experiencing important difficulties, with a strong reduction of cultivated surface ( $-12 \%$ of UAA) and employment ($27 \%$ ) in a decade. This is due to the combination of ageing, increased production costs and lower land productivity. In spite of this, the agricultural and food sectors are considered to be a strategic component of the economy of these areas, in part because they combine with important environmental endowments $(21 \%$ of the national protected areas, and 23 Natura 2000 areas). About $30 \%$ of nitrate vulnerable areas are also found in this typology of rural areas. The infrastructure endowment is very low in these areas, with regard to transportation, hospitals and internet connections. Moreover, tourism and hospitality infrastructures are considered to be insufficient. The area was strongly involved in the Leader+ initiative, with the municipalities interested in this policy representing about $37 \%$ of the population.

The rural areas with development problems are mostly located in the mountains and hills of the South. They are less densely populated, with a decreasing population $(-1 \%$ in a decade, with a peak in the South of $-6 \%$ due also to migration). While they include only $12 \%$ of the population, they cover $43 \%$ of the national surface, and $35 \%$ of the UAA. They also account for $20 \%$ of agricultural employees and $18 \%$ of the national agricultural value added. Agricultural productivity is low (1000 euro/ha) and does not guarantee economic viability. Consequently, land abandonment is very high. Development potential is generally seen to be related to local resources and tourism. These areas are marked by high unemployment rates and a higher than the average share of the population dependent on agriculture ( $8 \%$ compared with the national average of $5 \%$ ). They are, however, very important from an environmental point of view, with $62 \%$ of the Natura 2000 areas ( $21 \%$ of the area of this typology), and $68 \%$ of the protected areas. The infrastructure endowment of these areas tends to be very poor, however, and the Leader+ initiative is most concentrated here (covering about $63 \%$ of the population).

\subsection{Strength, weaknesses, opportunities and threats}

In spite of the high heterogeneity of the system, it is possible to identify some mainlines that form the strategic development of the agricultural sector in Italy. This exercise was performed on the occasion of the "Piano Strategico Nazionale per lo sviluppo rurale" (National strategic plan for rural development, MiPAAF, 2009).

The main strengths are identified in the high propensity to produce certified quality products and in the diffusion of organic and integrated agriculture. The growing connections with the food industry and tourism are also seen as important.

The main weaknesses are found in the insufficiently high economic performances which ultimately prevent the sector from being competitive (high costs, low value added per employee). Additional weaknesses are found in structural problems at the level of agriculture (small farm size) and poor performance of the agricultural and food chain in terms of price transmission, performance of processing plants, difficulties in organization and concentration of supply, uneven market power between agriculture and the downstream sectors. Ageing and low infrastructural endowment, particularly in some areas, add to this picture.

The main opportunities concern the changes in consumption patterns with more attention to healthy and ethical products. Opportunities are also seen in the wide range of policy measures encouraging restructuring, investment and chain organization, as well as in the wide scope for enterprise organization though emerging legal forms such as agricultural limited liability companies.

The main threats identified stem from the crisis of consumption of agri-food products and the strong competition on international markets by both EU and nonEU countries (e.g. southern Mediterranean countries).

\subsection{Agricultural policies}

The Common Agricultural Policy (CAP) is the main policy concerning agriculture in Italy. The total first pillar expenditure for Italy is about 4660 million euro, representing $11.1 \%$ of the total EU expenditure under this chapter (with a decrease of $3 \%$ in 2008 compared to 2007). According to the variety of farming systems, specialisations and structural characteristics, a very wide range of measures are implemented in Italy, with varying importance depending on prevailing local production systems.

However, the chapter that is by far the most important in the first pillar is the single farm payment (SFP), which accounted for 3206 million euro (69\% of first pillar payments) in 2008. In the same year, other direct payments accounted for 600 million euro (13\%), while the remainder of the first pillar is provided by direct intervention on agricultural markets (880 million euro, 19\%). The sugar restitution fund also played an important role with a 535 million euro payment. Following the Fischler reform, Italy opted for the total decoupling of cereal, oil and protein crops payment starting in 2005 . In the same year environmental 
cross-compliance was also introduced, tying SFP payments to compliance with a number of basic environmental regulations, and with keeping farmland in good agricultural and environmental conditions.

Pillar two measures, basically represented by Rural Development Plans (RDP) started in 2000 and aggregated a number of previous interventions classified either as structural or complementary measures. Italian RDP are cofinanced by the national government and have a total availability of 16,604 million euro for the programming period 2007-2013, which is about 2372 million euro per year. However, the implementation got off to a slow start and on March 31, 2009 only about 1359 million euro had been paid (less than 9\%). This is actually quite common in the implementation of all rural development plans; it also occurred at the beginning of the 2000-2006 programming period and in the mid nineties when the accompanying measures introduced by reg. EC 2078/92, 2079/92 and 2080/92 were implemented. Of the amount already paid, altogether, $81,3 \%$ of the total RDP funding is devoted to axis 2 measures, $16,3 \%$ to axis 1 and the remainder to axis 3 . This concentration of payments on axis 2 is largely due to the coverage of undertakings already established in the period 2000-2006, and which remain in force for the following period during to the length of the contracts (5 to 20 years), particularly in the field of agri-environmental measures.

\subsection{Public goods and agriculture}

Pierangeli et al. (2008) found that different areas of Europe undergo different "multifunctional specialisations" and that this is more evident when moving to the lower scale. They also classified EU countries according to their characteristics with respect to multifunctionality. In this exercise, Italy is included in a cluster with other Mediterranean countries (Greece, Spain and Portugal). This cluster is characterised by the relevant weight of the primary sector on GDP, rural diversification (underscored by the large diffusion of Leader+ activities) and by the emphasis on product valorisation and territorial identification, mainly by way of certifications of origin.

Public goods related to agriculture are mostly identified with environmental and landscape features in rural areas. In such contexts, MiPAAF (2009) identifies seven main areas of concern:

- biodiversity;

- water resources;

- climate change;

- soil;

- air quality;

- landscape;

- disadvantaged areas.

Let us consider the main components in turn.

Agriculture plays a major role in biodiversity conservation due to the high share of high natural value farmland (about $21 \%$ of the total UAA), mostly concentrated in Natura 2000 areas. However, the level of biodiversity is still decreasing, as shown mainly by bird populations. This is mostly caused by a simplification of most agricultural habitats, due to the intensification of farming activities or farmland abandonment.

Water is a critical resource in Mediterranean systems, and for agriculture in particular. About one third of Italian UAA is irrigable, while almost a half of the national value added from agriculture comes from irrigated crops. This high dependency on water causes agriculture to be by far the most important water using sector in Italy (roughly 50-60\% of total national water use), which encourages conflicts with other sectors for water resources. Water protection issues are mostly connected with qualitative issues in the North, and quantitative issues in the South. While surface water is for the most part in an acceptable status, the situation of groundwater is critical in many areas, particularly in the South where it is the source for $53 \%$ of water abstraction. Agriculture affects water quality mainly through nitrogen emissions (about $40 \mathrm{~kg} / \mathrm{ha}$ ) and quantity through abstraction for irrigation purposes. The use of chemicals in agriculture is characterised by an increase in total market value, but a decrease in quantity used. Irrigation water management is affected by major inefficiencies both in the distribution system and concerning on-farm irrigation systems.

Climate change is a relevant issue from the point of view of emissions/fixation of gasses contributing to climate change, and from the related point of view of energy production from biomasses. From the point of view of greenhouse gas (GHG) emissions, agriculture contributes only $6,5 \%$ of total Italian emissions. However, agriculture is the main source of emissions for Methane and Nitrous Oxide. From 1990 to 2006, emissions of these gasses have fallen by respectively 12 and $8 \%$. What is most important is that many agricultural systems can play a role in carbon fixation. This role is particularly important as the total GHG emissions in Italy in the period 1990-2006 have increased by $10 \%$ compared to an expected reduction by $6,5 \%$. In recent years a major emphasis has been devoted to the production of energy from biomass, mostly driven by poor agricultural profitability and the consequent search for alternative sources of income, and encouraged by both the value of green certificates and specific payments for energy-related investments under the RDP 2007-2013, axis 1.

Soil management issues are mostly characterised by the reduction of the cultivated area $(-16 \%$ in the last decade), mostly in the area cultivated with permanent pastures $(-26 \%)$. Soil quality is also a problem. In plain areas the main soil quality issue is related to the increase in phosphorous pollution due to fertilizers. In hill and mountain areas, soil degradation is mostly caused by the reduction of organic matter and soil erosion due to water flows. Practices such as organic agriculture have a major role in the preservation of soil. Organic agriculture represented about $9 \%$ of the national UAA in 2007, with a constant overall growth trend (it was $8 \%$ in 2000), but with contrasting trends among different crops (steady growth in fodder crops and a decline in grapes and fruit). 
With regard to air pollution, the main source from agriculture is ammonia emissions (NH3). The main source of such emissions is livestock production with about 54\%, followed by cultivation with $40 \%$. The ammonia emissions in agriculture between 1994 and 2006 have been reduced by $12 \%$, mainly due to a reduction in herd size. Agriculture is now seen as playing a major role in the fight against climate change.

Rural landscapes are a major feature of Italian agriculture, built over thousands of years, contributing to biodiversity conservation, cultural perceptions of rurality, quality perceptions the certification of products, and rural recreation activities. Rural landscapes have deteriorated in recent decades, particularly due to urban development and the simplification of crop-mixes. This trend was partly accompanied by unfavourable policy designs, which for decades were mostly oriented toward productive agriculture. Abandonment of marginal land and forests has also contributed to landscape degradation. In spite of the change in policy focus since the beginning of the 1990s, negative trends seem, altogether, to prevail.

Disadvantaged areas have been identified in order to implement the RDP measures on compensation for disadvantaged areas. They account for $61 \%$ of the national area, with percentages ranging from less than $40 \%$ to more than $90 \%$ in the Aosta Valley, Basilicata and the autonomous province of Bolzano. In terms of agricultural production units, they concern $59 \%$ of Italian farms. These areas have been characterised by constant depopulation and abandonment of agricultural activities in the last two decades. In contrast with this, the average farm area is also decreasing, although the trend can also be associated with a rationalisation of existing farming structures. Economic activities and infrastructure are also weaker in these areas.

This is particularly relevant in connection with the socioeconomic aspects of agriculture, already discussed in relation to the differentiation of rural areas above. Though less commonly connected to agricultural activities and policy, socio-economic aspects also contribute to the public role of agriculture. For example, they are tied to the various dimensions of employment, social networks and cultural characteristics that are strongly related with the differing importance of agriculture in different kinds of rural areas, as discussed in section 2.2.

\subsection{Policies related to multifunctionality}

Agri-environmental measures have dominated the scene of non-first pillar measures since 1992, and also since 2000 (with the Agenda 2000 reform), when they were integrated into the RDP. RDP now include a very wide range of policies related to various aspects of multifunctionality, ranging from payments for investment in diversification activities, to measures aimed at improving the quality of life in rural areas.

The main measures directly related to multifunctionality in terms of budget, are those included in axis 2 of the second pillar of the CAP.
During the period 2000-2006, expenditures for contracts established under reg. EC 2078/92 (agri-environmental measures) accounted for $31,6 \%$ of the total RDP expenditure and this summed up to the Measure F of the RDP (agrienvironment), which accounted for $19 \%$. As a result, about half of the RDP resources were devoted directly to providing incentives for the production of environmental services from agriculture. The next most relevant measures in terms of expenditure were those of Measure A (farm investment), with about $10 \%$ of the total expenditure over the period 2000-2006 (MIPAAF, 2007).

\section{Expected changes in the organisation of farming sectors from a generational perspective (20-25 years)}

The main features of the last decades which are expected to continue in the future are the process of exiting from agriculture, accompanied by major restructuring of farms, either through the sale or renting of land or the increased role of machinery renting companies.

This will be to some extent driven by CAP developments. In particular, if the main policy trend remains characterised by decoupling, competition on the global market will accelerate restructuring and exiting from the farming sector, resulting in a more and more dualistic agriculture sector in which well-connected and endowed competitive areas are opposed with less favoured areas.

Such effects will also increase the attention given to innovative farm and chain organisation (e.g. farmers' markets), and the quality of production.

This will occur against two background features: urban development and climate change.

Urban development has characterised the second part of the 20th century and strongly affected land prices and ownership strategies in agriculture. Settlement development is expected to continue, particularly in small villages in rural areas surrounding the main towns. This will affect both access to land and quality of life in rural areas.

Climate change will be a crucial issue in the mediumlong term. The crucial issues for Mediterranean agriculture will be related to water availability and the effects of temperature on evapo-transpiration. In addition, energy and carbon sequestration issues could yield opportunities for agriculture.

\section{Possible Future Multifunctionality Issues}

\subsection{Main thematic issues}

All the main thematic issues discussed above will maintain their relevance in the future. Among them, however, recent trends show a shift in attention toward water resources, climate change and energy production from biomass, and biodiversity. While this is consistent with the 
recent trends in EU policy (new challenges introduced by the Health Check of the CAP), a number of specificities exist with regard to the Italian context.

Water management concepts are changing under the pressure of the increasing frequency of drought events, and the implementation of the Water Framework Directive (60/2000). While water scarcity issues are expected to become more severe in the future, the commitment from agriculture to save or efficiently use water is becoming more important in the context of the mediation of allocation to other sectors.

Climate change and energy are seen as relevant opportunities for Italian agriculture. After the rush to open new facilities and provide incentives for energy production from biomasses, witnessed over the last five years, the next challenges will be devoted to ensuring economic viability of existing energy producing infrastructures, and understanding the most likely strategies for a consistent development of energy production.

Agriculture continues to be mostly competitive with biodiversity conservation, in spite of the emphasis on biodiversity as a resource. Biodiversity conservation usually implies putting constraints on agricultural production for which compensation is provided.

A key concern in reconciling the profitability of agriculture and biodiversity (as well as a number of other public good related concerns) is the role of organic agriculture. In fact, based on the experience of recent years, two different "types" of organic agriculture should be considered. On the one hand, there is economically viable organic agriculture, mostly related to high value products, with rather direct connections with consumers, and sometimes connected to diversification activities (i.e. rural tourism). On the other hand, there is policy-driven organic agriculture, which is often characterised by extensive lowinput crops, and mainly justified by payments provided by the RDPs, but unlikely to provide significant environmental benefits or market profits.

A connected issue is the role of quality products. The development of certifications has contributed to public (consumer) awareness and the recovery of typical high value added products. However, willingness to pay for quality and the effectiveness of certification is still modestly understood. In addition, the actual degree of connection between quality products and public goods is still largely to be qualified and demontrated.

Urban-rural interaction is also discovering new dimensions. Beyond the traditional and still relevant competition for land, a future issue is that of the actual integration of non-agricultural settlements into mainly agricultural areas and the role of agriculture related to local urban areas. While discussions in recent years have mainly been focused on the role of agriculture as a landscape producer, more recent attention on retaining profits for agriculture and reducing "food miles" has highlighted the role of local agriculture as a producer of food for local consumers, through farmer's markets and short chain solutions. The roles of agriculture are particularly relevant around urban areas characterised by high historical and landscape values and can develop a willingness to pay on the part of local non-agricultural populations (Torquati et al., 2008).

In recent years new attention has also been attracted to productive agriculture and innovation processes. This is due to the general policy context (CAP reform), the push for less protection and higher competitiveness in the market, as well as the strong structural change that is creating a growing number of large entrepreneurial farms that already hold a majority of production. These farms, though mostly open in terms of production processes, including multifunctional activities and policy driven production of public goods, are generally more oriented toward classical agricultural production, and in particular agricultural commodities benefiting from economies of scale.

A past and future issue is the role of diversification of farming activities in the context of multifunctional agriculture. For example, Finocchio and Esposti (2008) investigated diversification of farming activities in the Marche region of Italy, mainly with regard to deepening (organic farming, product processing, quality products (PDO, PGI, TSG), ISO, HACCP certification, and other kinds of certification) and broadening the kind of activities (rural tourism, farm contracting, participation in agri-environmental programs). They found that a move in the direction of multifunctional diversification is encouraged by small farm size, and dependent on location. In fact, this attitude seems also to grow over time. As far as policy is concerned, they found that the correlation with pillar I payments is negative and that the correlation with pillar II is very low, suggesting that diversification activities are more important for those farms which benefit less from CAP support.

An issue somehow touched marginally in the literature compared with the potential major relevance in the future is that of GMO acceptance and coexistence with organic and traditional production, in a context where a strong market strategy has been based on the qualification as GMO-free products and areas.

\subsection{Main policy (design) and research issues}

Two general policy and research issues can be identified in the lines of research already developed in the last two decades about the effectiveness and efficiency of policies directly aimed to provide incentives for the production of multifunctional goods by agriculture. They concern the documentation of jointness of such goods with agriculture and the ability to measure the changes actually attributable to policies.

On the first point, attention is drawn to the discrepancy between technically/economically demonstrated connections between agricultural, environmental and social effects, and the policy discourse surrounding agriculture, that often emphasises as a product of agriculture also weakly connected or competitive outputs. The trend of the 
weakening of the connection between households and farming, even in the most rural areas, emphasizes that also the jointness of agriculture with social concerns is weakening, at least for quantitative issues (e.g. employment concerns). Cultural linkages, on the other hand, are still strong though reshaped by explicit communication/marketing strategies, not always corresponding to the true historical identity of rural areas.

The inability to measure effectively the effects of multifunctionality-related policies strongly affects the policy debate throughout Europe. This concerns, for example, agrienvironmental measures (Finn et al., 2009). This is also related to a second issue associated with agri-environmental policy concerns, that is the determinants of participation, a theme also having attracted considerable attention in Europe (Defrancesco et al., 2008).

The introduction of cross compliance in 2005 has brought forward a number of new policy issues. While initially considered to be a very soft policy and basically dismissed on the research side as a simple matter of the obligation to fulfil existing requirements, it is beginning to raise major policy design questions. First, the costs of cross-compliance are relevant and become part of the decision making process at farm level. At the same time effectiveness is not assured and should be analysed in a moral hazard context, in particular considering the low level of monitoring. This leads us to the problem of the appropriate design for rarely verifiable prescriptions, incentives related to pre-established payments, and sanctions (Bartolini et al., 2008a). One additional issue related to cross-compliance is that agri-environmental prescriptions are now connected to the baseline represented by cross compliance, which enlarges the scope for locally negotiated constraints leading to public good production and, more importantly, calls for a joint design of first and second pillar environmental measures (Bartolini et al., 2008b).

A major issue for the future of multifunctionality will be the integration between policies. Relevant examples already in the present RDPs are measures that provide compensation for farmers subject to restrictions from the Water framework directive or Natura 2000. Similarly, cross-compliance measures rely heavily on existing regulations, as they refer in most cases to compulsory norms which have already been in place for several years.

In fact, a number of less visible connections exist throughout all second pillar measures. A large part of this integration is actually performed at the local level as both RDP and reference regulations are specified locally. This is the example of WFD, where measures are designed at the basin district level, which is close to, but never coincides, with the nuts II level where RDP (and partly crosscompliance) is designed in Italy.

This leads to the further problem of governance. Coordination at the local level involving a growing number of actors is increasingly required, and is already proving to be a difficult task. In addition, even within the same institution, an issue in coordination between different directorates may arise.
As well as the integration between policies, increased attention has been attracted in recent years by the effects of networking in the connection between agriculture and agrifood industry in either a chain or district perspective. This attention has been emphasised by the diffusion of Leader+ initiatives, that focus on networking, and has tended to move from "mere" economic networking to either the role of social networks and social capital (e.g. Medicamento and De Gennaro, 2006; Magnani and Struffi, 2009), and the emerging of "knowledge" networks related to development and innovation processes. Altogether, the recent literature seems to suggest an important space for the development in this direction, also taking into account of the increasing complexity of agricultural embedding in rural and non rural society and the pervasive role of globalised phenomena as determinants of local outcomes. A number of potential major issues are now being detected in this direction, but still insufficiently studied, such as Central EU elderly moving to buy houses in Mediterranean areas, "multi-country farms" split between Italy and the Balkans, non-EU immigrants up-taking farms as entrepreneurs, technologies flowing from outside (e.g. biogas digestors from Germany or cereal storage bags from Argentina.

\section{Discussion}

In recent decades agriculture in Italy has been characterised by a reduction in importance in the national economy and employment, accompanied by major structural change, though they are often poorly reflected in official statistics (e.g. farm size). Agriculture is strongly connected to the food industry, which is, on the contrary, a major component of the Italian economy.

The discussion about multifunctionality of agriculture in rural areas in Italy has developed around the two connected themes of the provision of public goods from agriculture (including the reduction in production of "public bads"), and the development of agricultural-rooted "non-conventional" agricultural activities (diversification). Policy, particularly the CAP, has been a major driver of such developments. However, the marketing strategy based on certified, high quality, environmental and socially friendly, traditional local products has also played an important role in this direction.

The future is characterised by high uncertainty, though some major trends seem to maintain their relevance, such as: farm structural change and the concentration of land in a smaller number of farms, price volatility, concentration of agricultural activities in the most productive rural areas, and attention to environmental and food quality.

In such a context, dichotomies between productionoriented and multifunctionality-oriented farms seem to remain and indeed be strengthened. The same contrasting attitude seems to increase in the contraposition between areas of specialised agriculture and areas of low income, high natural value agriculture.

A key issue concerns the market sustainability of the multifunctional roles of agriculture. In most cases such roles 
will remain highly policy dependent. As a consequence, a high attention needs to be paid to key emerging policy design issues, particularly concerning cross-compliance, coordination between first and second pillar of the CAP, and coordination between agricultural and other policies.

This is embedded in the wider issue of rural development and its profound diversification across the different areas of Italy.

\section{References}

Bartolini, F., Gallerani, V., Raggi, M. and Viaggi, D. (2008a). Effectiveness of cross-compliance under asymmetric information and differentiated compliance constraints, 2008 EAAE Congress, Gent, Belgium, August 26-29, 2008.

Bartolini, F., Gallerani, V., Raggi, M. and Viaggi, D. (2008b). Linking cross-compliance and agri-environmental schemes: a case study in Emilia-Romagna, 109th Seminar of the European Association of Agricultural Economists (EAAE) "The Cap After the Fischler Reform: National Implementations, Impact Assessment and the Agenda for Future Reforms, Viterbo, Italy, 20-21 November 2008.

Defrancesco, E., Gatto, P., Runge, F. and Trestini, S. (2008). Factors affecting farmers' participation in agri-environmental measures: a Northern Italian perspective. Journal of Agricultural Economics, 59, 114-131.

Finn J.A., Bartolini F., Bourke D., Kurz I., Viaggi D. (2009): Ex post environmental evaluation of agri-environmental schemes using experts' judgement and multicriteria analysis, Journal of Environmental Planning and Management, 52, pp. 717-737.
Finocchio R. and Esposti R. (2008). Determinants of farm diversification and interaction with the CAP. An application to FADN of Marche region (Italy). 12th Congress of the European Association of Agricultural Economists - EAAE 2008.

Istituto Nazionale di Economia Agraria (2008). Italian Agriculture in figures 2008, Rome.

Istituto Nazionale di Economia Agraria (2009). L'agricoltura italiana conta 2009, Rome.

Magnani N., and Struffi L. (2009). Translation sociology and social capital in rural development initiatives. A case study from the Italian Alps, Journal of Rural Studies 25, 231-238.

Medicamento U. and De Gennaro B. (2006). Social Networks and Supply chain Management in Rural Areas: A Case Study Focusing on Organic Olive Oil, Poster paper prepared for presentation at the International Association of Agricultural Economists Conference, Gold Coast, Australia, August 12-18, 2006

Ministero delle Politiche Agricole Alimentari e Forestali (MiPAAF) (2009). Piano Strategico Nazionale per lo sviluppo rurale, Rome.

Ministero delle Politiche Agricole Alimentari e Forestali (MiPAAF) (2007). Attuazione finanziaria PSR 2000-2006, Rome.

Pierangeli F., Henke R. and Coronas M.G. (2008). Multifunctional agriculture: an analysis of country specialisation and regional differentiation, 12th Congress of the European Association of Agricultural Economists - EAAE 2008.

Torquati B., Giacché G., Taglioni C., Musotti F. (2008). The effects of CAP reform on the periurban agricultural area in the plain of the city of Assisi, (Central Italy), 109th EAAE Seminar " The CAP after the Fischler reform: national implementations, impact assessment and the agenda for future reforms". Viterbo, Italy, 20-21 November 2008. 